\title{
Introduce Colles to Freshman in Mathematics Teaching
}

\author{
Jing Guan \\ Sino-European Institute of Aviation Engineers \\ Civil Aviation University of China \\ Tianjin, China \\ Guanjing_cauc@163.com
}

\author{
Zhou Xu \\ Sino-European Institute of Aviation Engineers \\ Civil Aviation University of China \\ Tianjin, China \\ Zhoulxu2@hotmai.com
}

\begin{abstract}
In this paper, we introduced a new type of teaching method which had not been used in university of China. This method originated from French engineers education, and had been executed for students in Sino-European Institute of Aviation Engineers from Civil Aviation University of China for 5 years. This method can efficiently improve teaching and learning effect.
\end{abstract} phase

Keywords-colles; engineers edcation in French; preparatory

\section{PRESENT SITUATION OF MATHEMATICS TEACHING FOR} FRESHMEN IN UNIVERSITY OF CHINA

Today, high education in china has basically changed from elite education to general education. Most high school graduates have the opportunity to receive university education. In 2008, , 57\% of graduating students in high school were admitted to various colleges and universities, in 2009 the figure was $62 \%$, while in 2010 it reached $69 \%$. On one hand, general education in university education improves the overall education level, and then improves the quality of the nation. On the other hand, the increasing of college admission rate year after year makes the contradiction caused by scarce hardware environment, teaching faculty and teaching supporting growing tension. This kind of scare in teaching resource impacts teaching quality in the process of general educational.

As for mathematics, significant differences between high school and university will be found for a freshman in university. Firstly, teaching method changed. When in high school, teachers give the focus of learning and lead students through doing a lot of exercises, thus strengthen memory and understanding of key problem. While in university, teachers try to train independent learning ability of students. Students are required to understand and grasp the focus by their own, use library and other open resources for review in order to digest what they have learned. Secondly, students find the learning content changed greatly. Higher mathematics system architecture is required to be built, but not some focus. A part of freshmen confuse to find the focus of learning, thus unable to keep up with the pace of learning.

\section{WE NEED AN EFFICIENT TEACHING WAY FOR AUXILIARY}

In fact, development of self-learning ability for all students in college education is inevitable. However, we must find that supervision and guidance for freshmen is slightly less in current college education. It is difficult for teacher to understand each student in his class, thus resulting in a low efficiency of teaching.

In this background, the emergence of a relatively efficient teaching way or auxiliary teaching methods is summoned to appear. With existing conditions, a part of elite higher education personnel could be cultured under the background of general education. It is aware of this, in 2010, national excellent engineer education and training programs strategic objectives was proposed and implemented in about 61 elite universities. Engineer education originated in France, which was created by Napoleon more than 200 years ago. Nowadays, sixty percent president and most management staff were graduated from engineering schools in France two hundred enterprises. French President Francois Mitterrand and Chirac both graduated from engineering school.

In fact, two phases made up of the whole engineering education. The preparatory phase is about 2 or 3 years, which focuses on mathematics and physics. The engineering phase focuses on internship. In preparatory phase, students are required to complete mathematics or physics learning content equals to the first two years taught in mathematics and physic department. Besides big lessons, exercises and exams, a type of regular oral exam called 'colles' is applied in teaching phase. This teaching method is different from traditional one-way flow teaching methods (teaching and listening). It is a feedback loop teaching methods which exists good communication between teachers and students.

Colles is implemented by big lesson teachers or exercise teachers. For each student one-hour oral examination is required every two or three weeks. Test sites can be in school classrooms or specialized colles classroom. Teacher ask questions and students give answer. The first part of colles usually contains definitions, theorems and related proof of the theorem learned recently. The second session, two or more question are provided by teacher. Usually, a number of small questions are contained in one big problem. Questions focus on close links between theorems and small questions. Purpose of session is to discover the shortage of students in the learning process. 


\section{SOME EXAMPLE FOR COLLES}

Here is one Colloes in Preparatory stage of Lycee Bellevue, an engineer school, Toulouse, France

Time: Monday 15:00-16:00 pm

Location: big lesson classroom

Organization: one teacher with three students.

Firstly, each student answered definition and theorems on the blackboard and given the necessary proof. Then the teacher gave subjects based on student's situation, which should be answer in given time. For good scores student, the questions can be arranged relatively difficult or more big. If the one answer the question quickly, another problem can be given. For bad score students, relatively easy subject and more hints should be provided.

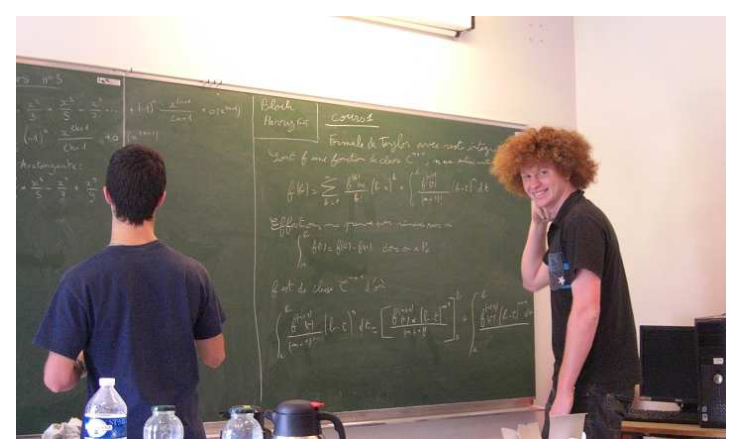

FIGURE I. STUDENTS OF LYCEE BELLEVUE IS DOING COLLES

\section{Question 1:}

Defination and theorem:

a)

Set $u \in L(E)$ where $E$ is espace vectoriel euclidien, what is the relation between $\operatorname{ker} u^{*}$ and $\operatorname{Im} u^{\perp}, \operatorname{Im} u^{*}$ and $\operatorname{ker} u^{\perp}$ ?

b)

$\mathrm{F}$ is S.E.V. of E, then what is the relation between $\mathrm{E}$ and $F \oplus F^{\perp}$, $\operatorname{dim}(F)+\operatorname{dim}\left(F^{\perp}\right)$ and $\operatorname{dim} E$ ?

Exercises:

Set $u \in L(E)$ where $E$ is espace vectoriel euclidien,

a)

Montrer $\operatorname{ker} u^{*}=\operatorname{Im} u^{\perp}$

b)

Suppose $u^{2}=0$, prove: $u+u^{*}$ inversible $\Leftrightarrow \operatorname{Imu}=$ Keru

This question is relative difficult.

\section{Question 2:}

Definition and theorem:

Set $u \in L(E), \quad M \in M_{n}(R)$, and $\beta$ is a base orthonormee of E t.q. $M_{\beta}(u)=M$, then $u \in \sigma(E) \Leftrightarrow M ?$

Exercises:

Set $\mathrm{E}$ is an espace euclidien and $f \in G L(E)$,

a) Prove there exist $f \in L(E)$ which transform a base orthogonale into another base orthonormee by $\mathrm{f}$.

b) $\quad$ Set $M \in G L_{n}(R)$, prove existe two matrices orthogonales $\mathrm{U}$ et $\mathrm{V}$ t.q. UMV is diagonale.

\section{Question 3:}

Defination and theorem:

Repeat Theorem spectral

\section{Exercises:}

Set $\mathrm{u}$ is an endomorphisme autoadjoint of an espace euclidien $\mathrm{E}$, where valuers propres $\lambda_{1}, \cdots, \lambda_{n}$ is ranged in ordre croissant. Prove that $\forall x \in E, \quad \lambda_{1}\|x\|^{2} \leq$ $\langle u(x), x\rangle \leq \lambda_{n}\|x\|^{2}$.

This topic is relatively easy.

\section{SOMETHING SHOULD BE PAID ATTENTION TO ABOUT COLLES}

In the problem-solving process, several minutes should be given to students for thinking. If students have questions about the problem, hints could be given until he finishes the question. After the student complete the topic, reviews and scores about each student should be given right now. Both difficulty and completion condition should be considered.

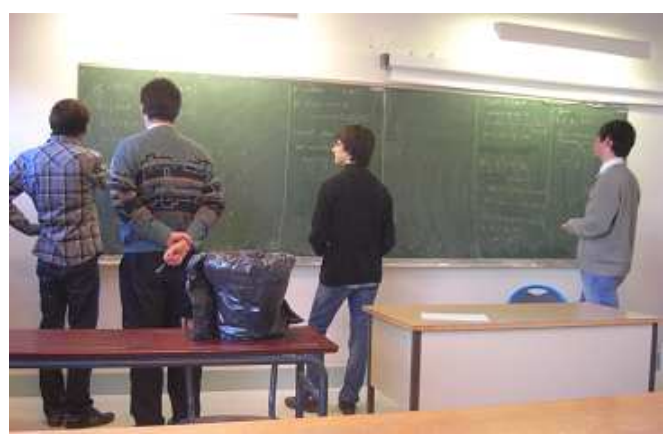

FIGURE II. THE TEACHER GAVE HINT TO STUDENTS IN LYCEE BELLEVUE 
For teachers, the topic of colles should be representative, especially those inspiring, and analytical problems. More small problems with internal relationship are better. Those questions with too difficult prove or computation should be avoided.

Unlike written exam, colles focuses on the exchange between teachers and students. Therefore, in the interview process, teachers pay attention to ask questions in order to find shortage of each student in their learning, in which definitions and theorems understanding, analysis process are included.

\section{IMPLEMENT OF COLLES IN SIAE OF CAUC}

Currently, colles have been executed for five years in SIAE of CAUC, and achieved good teaching results. On one hand, it helps students to discover learning deficiencies, adjust focus in time, and thus supervise the study effectively. On the other hand, it helps teachers to grasp every student's learning, and thus adjust instruction based on the student and improve the efficiency of teaching. Some students may glad to attend other student's colles in order to understand key point and learn more classic questions.

Colles is a mirror reflection both inadequate in teaching and learning. It is also an excellent platform for dialogue. In case of shortage of educational resources, it is possible to improve communication and teaching effect. Colles can not replace big lessons and exercise lessons, while it can be powerful supplement for them.

\section{ACKNOWLEDGMENT}

Thanks for those mathematics teachers in Lycee Bellevue, of Toulouse when I stayed in French in 2010. I learned many teaching methods and other knowledge there, thank you!

\section{REFERENCES}

[1] ZHENG Yu-xin. Problem Solving and Mathematics Education. JOURNAL OF MATHEMATICS EDUCATION, VOL 18, 1-4.

[2] Mervis, Jeffrey. Transformation Is Possible If a University Really Cares. SCIENCE. Vol. 340, 292-296.Cook, Elzbieta; Kennedy, Eugene; McGuire, Saundra Y. Effect of Teaching Metacognitive Learning Strategies on Performance in General Chemistry Courses. JOURNAL OF CHEMICAL EDUCATION, Vol. 90, 961-967.

[3] Serna M., Edgar; Serna A., Alexei:Is it in crisis engineering in the world? A literature review. REVISTA FACULTAD DE INGENIERIAUNIVERSIDAD DE ANTIOQUIA, VOL 66, 199-208.

[4] Glas, Eduard. Mathematics Education and the Objectivist Programme in HPS. SCIENCE \& EDUCATION, vol 22, 1315-132

[5] Barbin, E. Histoire des Mathe 'matiques: Pourquoi? Comment? Bulletin AMQ, Vol 37, 20-25.

[6] Garneli, B.; Giannakos, M.N. Chorianopoulos, K. Learning by Playing and Learning by Making Serious Games Development and Applications. 4th International Conference, SGDA 2013 